\title{
An Empirical Study on the Reform of Talent Cultivation Mode of Material Science in University Based on PBL
}

\author{
Fang Wei ${ }^{1, *}$ \\ ${ }^{1}$ Wuhan University of Technology, Wuhan, China, 430074 \\ *Corresponding author: 3033523@qq.com
}

\begin{abstract}
The purpose of this study is to research on the reform of talent cultivation mode of material science in university. The construction of knowledge system and curriculum system is the important part in the program of cultivating talents and the course construction projects vary in different institutions with different trade backgrounds and talent cultivation plans. The Problem-Based Learning (PBL) is used for constructing a specific model for the material science major and the empirical study is done in the experiment part. The result shows that the PBL model can improve the efficiency and effectiveness in the reform process of talent cultivation mode of material science in university.
\end{abstract}

\section{Introduction}

At the quick change time, organizational learning and learning organization are considered as the best methods for improving the organization learning ability, accommodating the existent environment of the quick change, but the implement is difficult, the long-term success cannot be obtained. For the reason, it is for the education people obtained have not given them the real learning, thus forming the barrier of the organizational learning, this problem should be solved at the procedure of education. At the same time, after the popularization of high education in China, the talent cultivation model cannot adapt the change situation; every university faces the pressure of talent cultivation and occupation. So under the view of high education, guided by the theory of organizational learning and learning organization, using systematical idea, integrated theory and practice studies, the dissertation has the importance on studying the talent cultivation model in learning university.

The talent cultivation model is composed of four factors, i.e. target, procedure, system and evaluation of cultivation. Through analysis of distance measuring model for talent cultivation, it can be found that there have differences between the actual result and expectation of talent cultivation in university, which is disadvantageous for the realization of talent cultivation model. PBL is problem-Based Learning short, usually translated as "problem-based learning." In material education, PBL concept is often used as a teaching method, teaching mode or teaching philosophy to use. "Classic" PBL refers to material students by solving ill-structured problems material cases to learn a learning strategy material curriculum. PBL has the advantage of changing the traditional teaching mode passive learning to active learning, group members mutual division of labor, through various channels to find their own solution to the problem of information, students learn the necessary knowledge in the process of solving problems, helping to train material students independent the ability to learn and lifelong learning, communication skills, teamwork, spirit of humane care and practical application of the ability to solve difficult material problem [1].

In recent years, with the advancement of education reform, education and more attention from the perspective of culture clinicians were practicability knowledge education of material students. Education has changed from "cramming" the traditional teaching to the "issue-based" PBL teaching methods [2-5]. PBL this new teaching model has been affirmed in the world of material education, and gradually become the new direction of material education mode reform. Therefore, the problem how to apply this model to our national material practice teaching effectively, improve the exist problems in the implementation of PBL teaching is worthy of thinking for every material educators.

The current principal contradiction in our material education is no longer a shortage of material personnel quantity, but the quality of the material personnel to improve. Whether it is from our social, economic, scientific and technological development and higher requirements for the proposed health, or from the enhanced competitiveness of international cooperation and urgent material needs, all we need to improve the quality of material education, training material talents. As a country in the world of higher material education more popular, with the development of foreign exchange, China's material education gradually internationalized [6]. 
Educational reform in developed countries focus on the reform of teaching methods, and reforms in developing countries is mainly reform of teaching content. Currently, the United States as a typical representative of the North American material education has a leading position in the world, after 200 years of rapid development and several major material education reform, has been completed and an effective mechanism and outstanding material education of material personnel education model is rest of the world in material education reference point [7].

\section{The Framework of PBL}

With the social development and technological progress, the material model from the biomaterial model into a biopsycho-social material model, marking a healthy material science, has entered a new period of development, promote the transformation of medicine all fields to accelerate prevention, updated diagnosis and treatment technology, so that the whole of material science fundamentally changed the face of occurrence. Each branch of medicine continue to expand and lead to mutually cross between disciplines continue to rise to a large number of interdisciplinary and multidisciplinary material curriculum Division is getting smaller, new technologies are emerging, material education is facing new challenges.

PBL is problem-based learning. PBL material education and the traditional model of material education are taught based learning (Lecture-Based Learning, LBL) that is very different. PBL in the late 1960s produced in Canada McMaster University School of Medicine, in the late 1980s in North America gained rapid development. 1991, 70 percent of US material schools have adopted varying degrees PBL mode of teaching. Since the 1990s, parts of school of medicine in European have begun to experiment PBL curriculum. University of Hong Kong in 1997 and started teaching PBL, PBL teaching currently account for $60 \%$ of all material school education and Harvard Material School have all been substituted LBL application of PBL teaching.

The basic equation for the routing algorithm is shown below:

$$
\overline{x_{i}}=\frac{x_{i}-b_{i}}{a_{i}-b_{i}}
$$

Experimental data to determine, we can also experience the value of the formula (2) the decision.

$$
n=\log _{2} m
$$

Hidden node output is calculated as follows:

$$
h_{j}=f\left(\sum_{i=1}^{m} w_{i j} x_{i}-\theta_{j}\right)
$$

The output of the output node is calculated as follows:

$$
f\left(\sum_{i=1}^{m} w_{i j} x_{i}-\theta_{j}\right)=f\left(f\left(\theta_{j}\right)\right)
$$

Where in $\theta$ is an output node threshold.

Put Equation (3) into Equation (4), then we can get the S-type function:

$$
f\left(\sum_{i=1}^{m} w_{i j} x_{i}-\theta_{j}\right)=f\left(f\left(\theta_{j}\right)\right)
$$

In the structure of GA algorithm, we can get the optimization equation as the following equation (6):

$$
h_{j}=\exp \left(-\frac{\left\|X-C_{j}\right\|}{2 b_{j}^{2}}\right), \quad j=1,2, \ldots, m
$$

\section{The Experiment and Data Analysis}

PBL pedagogy emphasize problem-based learning, students of all learning content around the "problem" This spindle start. It is mainly through "OK Threads $->$ analysis of the problem $->$ gathering information $->$ self-discussed $->$ Establishment Solutions -> summary evaluation and feedback" and other steps will introduce students to the problem situation. Pay attention to inspire and induce students to form a master self-learning ability and ability to solve problems in the whole process of material teaching. Based on the completion of each student while addressing the issue of teaching, and also completed the reproduction of knowledge, deepen the knowledge and understanding of the consolidation. Therefore, PBL teaching method has its unique advantages and effects in material teaching, mainly as follows:

(1) Help to stimulate students' interest in learning, improve learning efficiency

In PBL teaching mode, teachers will introduce students to the problem situation, students become problem-solving real "masters." By the classroom portion of the initiative to the students, not only to provide an opportunity for students 
to active learning, promote student autonomy, actively speak, to fully express their views, but also to develop independent learning ability to obtain knowledge and discovery issues, pole greatly improves the students' interest in learning.

(2) Help improve the overall quality of students

Based on material teaching and training by PBL teaching method designed to enable students not only have much to gain in terms of material expertise, and through active participation and problem solving can cultivate students' consciousness, innovation, competition and team spirit, in line with institutions of higher learning to implement concepts and requirements of quality education.

(3)Help build a theoretical study and practice cohesive platform

Problem-solving process, you need to curricular and extra-curricular, internal and external, direct and indirect experience closely together, gathering information through various channels, the expansion of knowledge to solve problems. Such training with a problem to solve the problem in training in learning, learning theory and practice can make a good combination of cognitive; improve the ability of students to apply theory to solve practical problems.

(4) Contribute to teachers to improve their professional quality and achieve a total growth of teachers and students

Figure 1 shows the comparison between effectiveness and sustainability of teaching methods in inside and outside, women and children and figure 2 shows the students' appraisal about credibility and sustainability of skill test.

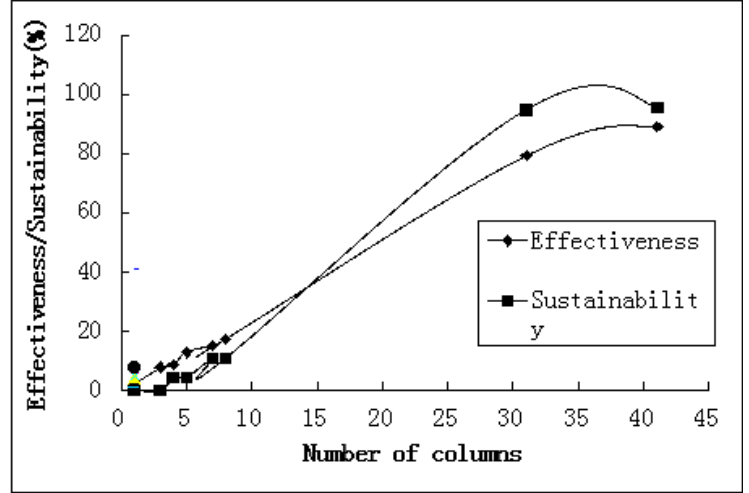

Fig. 1. The comparison between effectiveness and sustainability of teaching methods.

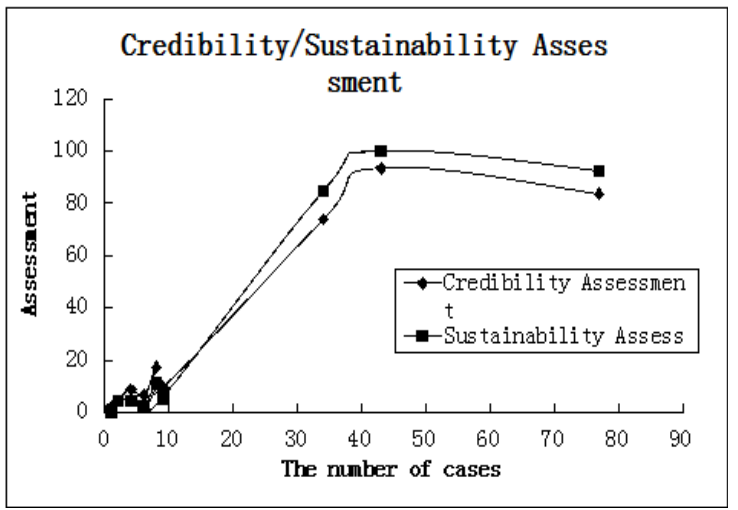

Fig. 2. The students' appraisal about credibility and sustainability of skill test.

In PBL teaching methods, problem-driven, integrated practice will not only help students to information sources and information tools to understand and use, and help students information analytical thinking and inquiring mind, to enable students to think independently, initiative exploration, self-discovery opportunities

Practice runs found because of differences in English reading ability, the experimental group students to master English to retrieve most difficult to retrieve than the Chinese, but to master the Chinese improve the ability to retrieve them also helped Further, since the practice time is short, in less time in evidence-based material education, students grasp the depth and difficulty enough, but less than nothing if the student to be familiar with the basics of evidencebased material education, such as the concept of authenticity background step evaluation of the implementation, but also basic to teaching results of the study. 


\section{References}

1. Jing Liangyou. Impact of heterogeneous cooperative learning groups on the students with learning difficulties in English studying. Teaching and performance management: theory version, (2013): 72-74.

2. Xie Qun, Zhang Yubin, Zhang Jibiao, etc. Cluster analysis and comprehensive evaluation on summer coastal marine environment quality of Leizhou Peninsul. Marine Environmental Science ,33 (2014): 543-549.

3. Zhao Dongling, Feng Yanruo, Pan Zhengyun. Research on clustering analysis based Algorithm K- grid, Journal of Technology, 30(2014):175-178.

4. Gong Liyan, Meng Xianjun. Quality evaluation of apple processing based on Principal Component Analysis and Cluster Analysis, Agricultural Engineering, 30 (2014): 276-285.

5. Zouyao, Qi Guinian, Liu Tingting, etc. Ingredients and cluster analysis on the principal componentr of Sichuan ottawa heap of black tea quality, Food Industry Technology, (2014): 304-307.

6. Wu He. Examining students' online interaction in a live video streaming environment using data mining and text mining. Computers in Human Behavior, (2013), pp. 291-304.

7. Wei Kuang Lai, Yi-Uan Chen, Tin-Yu Wu, Mohammad S. Obaidat. Towards a framework for large-scale multimedia data storage and processing on Hadoop platform. The Journal of Supercomputing, (2014), pp. 681-696. 